Wilson, B. W. \& Danforth, W. F. (1958). J. gen. Microbiol. 18, 535-542

\title{
The Extent of Acetate and Ethanol Oxidation by Euglena gracilis
}

\author{
By B. W. WILSON* AND W. F. DANFORTH \\ Biology Department, Illinois Institute of Technology, Chicago, Illinois, U.S.A.
}

SUMMARY: Euglena gracilis utilizes acetate and ethanol as energy and carbon sources. The $\mathrm{O}_{2}$ consumption due to acetate was equivalent to a $42 \%$ oxidation of the available acetate. $\mathrm{CO}_{2}$ production in the presence of acetate was consistent with the assumption that acetate is simultaneously oxidized and converted to carbohydrate.

Addition of ethanol resulted in an $\mathrm{O}_{2}$ consumption equivalent to a $39 \%$ oxidation of this substrate. The $\mathrm{CO}_{2}$ production due to ethanol was $0.93 \mu$ mole per $\mu$ mole of ethanol, more than double the amount predicted if carbohydrate is the sole synthetic product of ethanol metabolism.

Conditions known to change the rate of respiration, such as composition of growth media, incubation $\mathrm{pH}$, and the adaptation to acetate of ethanol-grown cells, had no effect upon the extent of ethanol and acetate oxidation.

Euglena gracilis is a member of a physiological group of protozoa termed the 'acetate flagellates', characterized by their excellent growth with acetate as the sole carbon source, and their poor utilization of glucose and related compounds (Hutner \& Provasoli, 1951). Until recently, the mechanisms regulating the oxidative metabolism of the acetate flagellates had been little investigated.

Lewin (1954) described adaptive changes in the oxidation : assimilation ratio of acetate in Chlamydomonas dysosmos. Danforth \& Wilson (1957) reported that Euglena, when grown upon acetate as a carbon source at $\mathrm{pH} \mathrm{7 \cdot 3}$ (Acgrown), oxidized acetate with a higher and less $\mathrm{pH}$-sensitive rate than did cells grown upon ethanol as a carbon source at $\mathrm{pH} \mathrm{3.5} \mathrm{(Et-grown).} \mathrm{In} \mathrm{addition,}$ some Et-grown cultures adapted to acetate, acquiring rates of acetate oxidation characteristic of Ac-grown cells.

A study of the extent of acetate and ethanol oxidation was undertaken for the purpose of obtaining basic information concerning the relationships of the energetic and synthetic activities of Euglena, and to ascertain whether conditions known to vary the rate of acetate respiration would also vary the extent of acetate oxidation.

\section{METHODS}

A streptomycin-bleached (non-photosynthetic) strain of Euglena gracilis var. bacillaris, the same as used in previous studies, was maintained in $10 \mathrm{ml}$. stock tubes on an acetate + tryptone medium at $\mathrm{pH}$ 7·3. Experimental cultures were grown under the two conditions listed in Table 1; Et-grown cells were grown on an ethanol + tryptone medium adjusted to $\mathrm{pH} 3 \cdot 5$; Ac-grown cells were grown on the above-mentioned acetate+tryptone medium at $\mathrm{pH} \mathrm{7.3.}$

* Present address: Department of Zoology, University of California, Los Angeles, California, U.S.A. 
Details of the growth procedures have been published elsewhere (Danforth \& Wilson, 1957).

All cultures were incubated at $18-23^{\circ}$ until visual inspection indicated good growth, usually within 7-14 days.

Table 1. Composition of groreth media

$\begin{array}{lcc} & \text { Ac-grown } & \text { Et-grown } \\ \text { Bacto-tryptone (Difco) } & 5 \text { g./l. } & 5 \mathrm{~g} / \mathrm{l} . \\ \text { Na acetate } & 18 \cdot 4 \mathrm{mM} & 0 \\ \text { Ethanol } & 0 & 18 \cdot 4 \mathrm{mM} \\ \text { pH } & 7 \cdot 3 & 3.5\end{array}$

The cells were then harvested and washed by centrifugation, and suspended in distilled water. A sample of this suspension was removed, fixed with ethanolic $\mathrm{HgCl}_{2}$, and counted in a haemocytometer.

Experimental solutions of $\mathrm{Na}$ acetate $.3 \mathrm{H}_{2} \mathrm{O}$ and ethanol ranged from $0 \cdot 8$ to $120 \mathrm{~mm}$; only the acetate solutions were adjusted for $\mathrm{pH}$. The buffer for all determinations was an equimolar mixture of tris(hydroxy-methyl)aminomethane and phosphate yielding a final concentration of 0.011 M. Experiments were run at $\mathrm{pH} 5 \cdot 5$ or $\mathrm{pH} \mathbf{7 \cdot 3}$.

Determinations were conducted with a Warburg apparatus at $26 \cdot 1^{\circ}$, having a shake rate of $120 / \mathrm{min}$. and a gas phase of air. $\mathrm{O}_{2}$ consumption was measured with $0.1 \mathrm{ml}$. of $14 \% \mathrm{NaOH}$ or $\mathrm{KOH}$ in the centre well. $\mathrm{CO}_{2}$ production was measured by the direct method (Umbreit, Burris \& Stauffer, 1949) replacing the alkali in the centre well with water. The time course of $\mathrm{CO}_{2}$ production was

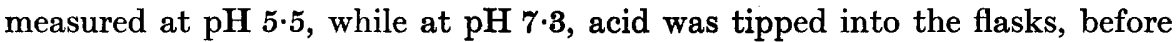
and at the completion of an experiment, to ascertain the total amount of $\mathrm{CO}_{2}$ evolved.

To determine the extent of acetate and ethanol oxidation cells and buffer were added to the main compartment and 2-20 $\mu$ mole substrate in $0.5 \mathrm{ml}$. were added to the side arm. The substrate was tipped into the main compartment after at least a 20 min. equilibration period, and the $\mathrm{O}_{2}$ consumption was recorded until the respiration had returned to the endogenous level. The total amount of $\mathrm{O}_{2}$ consumed due to the added substrate was calculated by subtracting the $\mathrm{O}_{2}$ consumed by an endogenous control during the course of the experiment.

These values were then plotted against the amounts of substrates added, and the slope of a line of best fit, using the Least Squares method, gave a value for the average $\mathrm{O}_{2}$ consumption per $\mu$ mole of substrate. The percentage of the substrate oxidized was calculated by dividing the average $\mathrm{O}_{2}$ consumption by the $\mathrm{O}_{2}$ consumption expected if the substrate were $100 \%$ oxidized $\left(3 \mathrm{O}_{2}\right.$ : ethanol, $2 \mathrm{O}_{2}$ : acetate $)$.

\section{RESULTS}

Euglena has a low, but measurable, rate of respiration when incubated in the absence of substrate. The respiration rate increases and remains constant for some time when an oxidizable substrate is added to the cells. After the respira- 
tion rate returns to the endogenous level, all the substrate is assumed to be removed from the medium. Figure 1 illustrates this behaviour in the case of Ac-grown cells, incubated with varying amounts of acetate.

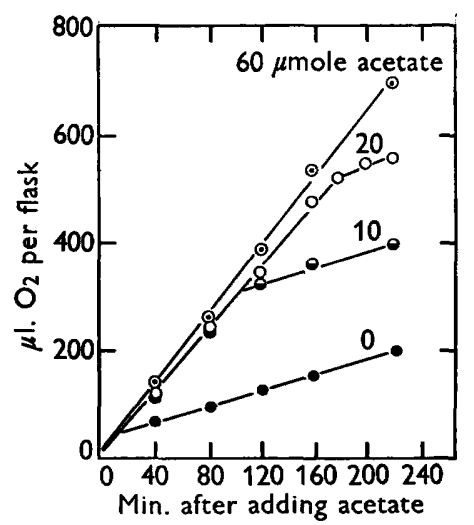

Fig. 1

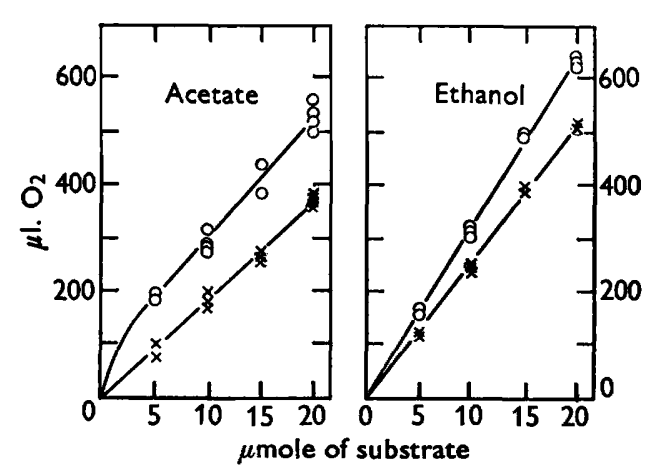

Fig. 2

Fig. 1. $\mathrm{O}_{2}$ consumption of Ac-grown cells on acetate. $0,10,20,60 \mu \mathrm{mole}$ of acetate added at zero time. Cells incubated at $\mathbf{p H} \mathbf{5 \cdot 5}$.

Fig. 2. Relationship between total $\mathrm{O}_{2}$ consumption of Euglena and amount of substrate added. $O$, assuming endogenous respiration suppressed by substrate; $\times$, assuming endogenous respiration continues during substrate oxidation. Data for acetate include 13 determinations from 4 separate experiments; for ethanol, 11 determinations from 3 experiments.

In order to calculate the efficiency of substrate metabolism by Euglena, it is necessary to determine whether the endogenous metabolism is inhibited during substrate oxidation, as has been reported for other organisms (Barker, 1936; Syrett, 1951). If the endogenous metabolism is suppressed by the presence of exogenous substrate, all the oxygen consumed during the presence of substrate must be attributed to substrate oxidation, while if the endogenous metabolism continues unchanged, the endogenous oxygen consumption must be subtracted from the total consumption in order to determine the oxygen consumption due to the substrate. Figure 2 presents data bearing on this problem. In this figure the same data are plotted in two ways: first on the assumption that the endogenous respiration is suppressed in the presence of substrate, and also on the assumption that the endogenous respiration continues unchanged. In the case of ethanol oxidation, both assumptions result in a constant ratio of oxygen consumption to substrate, while for acetate only the assumption that endogenous respiration continues yields such a constant ratio.

As Syrett (1951) has pointed out, under certain conditions both assumptions concerning the behaviour of the endogenous respiration in the presence of substrate may produce a constant ratio of oxygen consumption:substrate consumption, and in such cases, this criterion is of no value in distinguishing between the two alternatives. This is clearly the case for ethanol oxidation by Euglena. In the case of acetate, on the other hand, only the assumption 
that endogenous respiration continues during substrate oxidation gives a constant oxygen : substrate ratio.

It is concluded, therefore, that endogenous metabolism continues unchanged during oxidation of exogenous acetate. In the case of ethanol, no direct evidence supports such a conclusion, but since it seems likely that the two substrates would have similar effects upon the endogenous metabolism, it is assumed that neither acetate nor ethanol suppresses the endogenous metabolism.

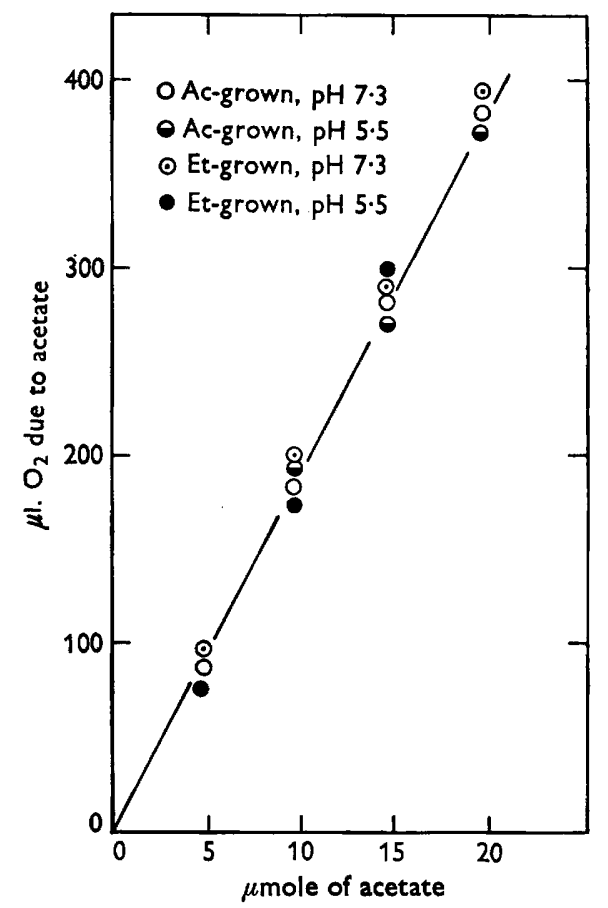

Fig. 3. The extent of acetate oxidation by Euglena. Values of a single class (e.g. Ac-grown cells at $\mathrm{pH} 7 \cdot 3$ with $10 \mu$ mole of acetate) averaged together. Slope is $18 \cdot 8 \mu \mathrm{l} . \mathrm{O}_{2}: \mu$ mole acetate, equivalent to a $42 \%$ oxidation of acetate.

In Fig. 3, the $\mathrm{O}_{2}$ consumption due to acetate, in a series of 44 trials, is plotted against the initial amounts of acetate added. Experiments were conducted with Et-grown and Ac-grown cells, incubated at pH 5.5 and 7.3. Cell concentrations ranged from $1.5 \times 10^{6}$ to $10 \times 10^{6}$ cells per flask. Acetate amounts ranged from 0.8 to $20 \mu$ mole. The slope of the line of best fit is $18 \cdot 8 \mu \mathrm{l} . \mathrm{O}_{2}$ per $\mu$ mole of acetate added, and is equivalent to the oxidation of $42 \%$ of the available acetate.

Adaptation to acetate had no effect upon the extent of acetate oxidation. Figure 4 illustrates the events during the adaptation to acetate of cells from an 8-day-old culture of Et-grown cells. The rate of acetate respiration increased $44 \%$, but the extent of acetate oxidation was no different from that found in the absence of adaptation. 
The time course of $\mathrm{CO}_{2}$ production, determined at $\mathrm{pH} 5 \cdot 5$, was linear (except during adaptation), and the respiratory quotient of acetate oxidation was $1.01 \pm 0.08$, independent of the experimental conditions. The results of 15 trials, at $\mathrm{pH} 5.5$ and 7.3, of Ac-grown and Et-grown cells, are tabulated in Table 2. Adaptation to acetate, which occurred in 7 of the 15 trials, had no effect upon the respiratory quotient.

Table 2. The respiratory quotient of Euglena on acetate

\begin{tabular}{|c|c|c|c|}
\hline \multirow[b]{2}{*}{ Growth substrate } & \multirow{2}{*}{$\begin{array}{c}\text { Acetate } \\
\text { (mM) }\end{array}$} & \multicolumn{2}{|c|}{ Respiratory quotient } \\
\hline & & pH 5.5 & pH $7 \cdot 3$ \\
\hline Ethanol & $\begin{array}{l}30 \\
30^{*} \\
10^{*} \\
30^{*} \\
30^{*} \\
30^{*} \\
30\end{array}$ & $\begin{array}{l}1 \cdot 00 \\
1 \cdot 10 \\
1 \cdot 06 \dagger \\
0 \cdot 75 \\
- \\
- \\
0.93 \dagger\end{array}$ & $\begin{array}{l}- \\
- \\
\overline{1.06} \dagger \\
0.90 \dagger \\
0.96 \dagger \\
0.91 \dagger\end{array}$ \\
\hline Acetate & $\begin{array}{l}30 \\
30 \\
30\end{array}$ & $\begin{array}{l}1 \cdot 00 \\
1 \cdot 17 \\
1 \cdot 06 \dagger\end{array}$ & $\begin{array}{l}-\overline{1 \cdot 35} \dagger \\
1 \cdot 04 \dagger\end{array}$ \\
\hline Average & & $1 \cdot 01$ & $1 \cdot 04$ \\
\hline Average (all values) & & $1.02 \pm 0.09 \ddagger$ & $(9 \%)$ \\
\hline
\end{tabular}

The extent of ethanol oxidation was determined at pH $\mathbf{5 . 5}$ and $7 \cdot 3$, using Et-grown and Ac-grown cells. Cell concentrations ranged from $2 \cdot 0 \times 10^{6}$ to $7 \cdot 0 \times 10^{6}$ cells per flask, and the initial amounts of ethanol ranged from 2.5 to $30 \mu$ mole. In Fig. 5, the $\mathrm{O}_{2}$ consumption due to ethanol is plotted against the initial amounts of ethanol. The slope of the line of best fit is equivalent to a $39 \%$ oxidation of the ethanol added to the cells.

The time course of $\mathrm{CO}_{2}$ production, in the presence of ethanol at $\mathrm{pH} 5 \cdot 5$, was linear with both Et-grown and Ac-grown Euglena. The results of 12 trials, at low and high $\mathrm{pH}$, using Et-grown and Ac-grown cells, presented in Table 3, yield $0 \cdot 33 \pm 0 \cdot 04$ as the respiratory quotient for ethanol oxidation, independent of the experimental conditions.

Since there is no direct evidence that the endogenous metabolism continues during the oxidation of ethanol, the data for ethanol oxidation have also been calculated on the assumption that endogenous respiration is suppressed in the presence of exogenous ethanol. Under this hypothesis, the pertinent values become: $\mu \mathrm{l}$. $\mathrm{O}_{2}$ per $\mu$ mole ethanol, $32 \cdot 5 \pm 1 \cdot 2$; respiratory quotient on ethanol, $0 \cdot 40 \pm 0 \cdot 004$.

\section{DISCUSSION}

There is a certain circularity in concluding that the endogenous metabolism continues during acetate oxidation because this assumption gives constant oxygen:substrate ratios and then using data corrected on the basis of this conclusion to demonstrate that oxygen:acetate ratios do not change with 


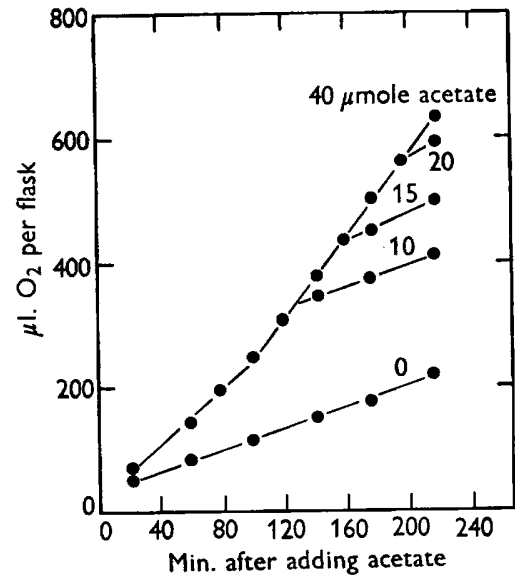

Fig. 4

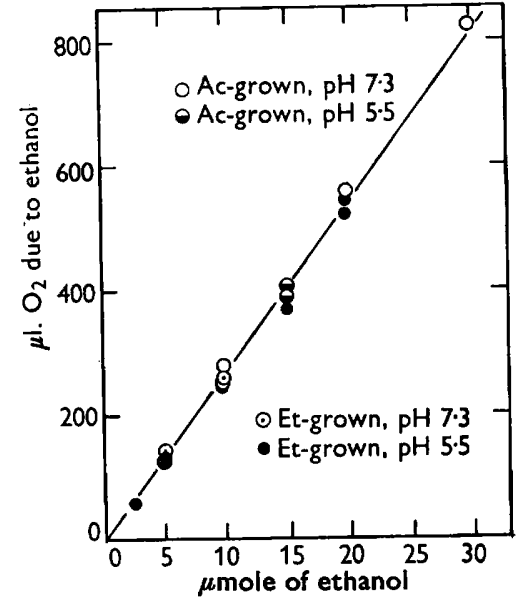

Fig. 5

Fig. 4. Effect of adaptation to acetate on extent of acetate oxidation. Et-grown cells, incubated at $\mathrm{pH} 7 \cdot 3$ with $0,10,15,20,40 \mu$ mole of acetate. Average $\mu \mathrm{l}$. $\mathrm{O}_{2}$ due to acetate: $\mu$ mole acetate (for $10,15,20 \mu$ mole acetate) is $18 \cdot 8$.

Fig. 5. The extent of ethanol oxidation by Euglena. Slope is $26 \cdot 3 \mu \mathrm{l} . \mathrm{O}_{2}: \mu$ mole ethanol, equivalent to a $39 \%$ oxidation of ethanol.

Table 3. The respiratory quotient of Euglena on ethanol

\begin{tabular}{|c|c|c|c|}
\hline \multirow[b]{2}{*}{ Growth substrate } & \multirow{2}{*}{$\begin{array}{c}\text { Ethanol } \\
\text { (mM) }\end{array}$} & \multicolumn{2}{|c|}{ Respiratory quotient } \\
\hline & & pH 5.5 & $\mathrm{pH} \mathrm{7 \cdot 3}$ \\
\hline Ethanol & $\begin{array}{r}30 \\
30 \\
5 \\
30 \\
30\end{array}$ & $\begin{array}{l}0.29 * \\
0.41 \\
0.28 \\
- \\
-\end{array}$ & $\begin{array}{l}0.23^{*} \\
\overline{-} \\
0.32 \\
0.32\end{array}$ \\
\hline Acetate & $\begin{array}{r}\mathbf{3} \\
\mathbf{3 0} \\
\mathbf{3 0} \\
\mathbf{3 0} \\
\mathbf{3 0}\end{array}$ & $\begin{array}{c}\mathbf{0 . 3 1} \\
\mathbf{0 . 3 4} \\
\mathbf{0 . 3 4} * \\
- \\
-\end{array}$ & $\begin{array}{l}- \\
\overline{-} \\
\mathbf{0} \cdot 40^{*} \\
0 \cdot 34 \\
0 \cdot 37\end{array}$ \\
\hline $\begin{array}{l}\text { Average } \\
\text { Average (all values) }\end{array}$ & & $\begin{array}{l}0 \cdot 33 \\
0 \cdot 33 \pm 0.04 \dagger\end{array}$ & $\begin{array}{l}0.33 \\
(12 \%)\end{array}$ \\
\hline
\end{tabular}

* Acid-tipped method. † Average deviation.

environmental conditions. In our opinion, recognition of this circularity does not seriously weaken the conclusions. If the extent of oxidation of acetate actually varied, there is no reason to believe that any simple assumption concerning the endogenous respiration should give constant ratios. Moreover, it is apparent from Fig. 2 that the variation in oxygen: substrate ratios introduced by using the 'wrong' assumption concerning the endogenous respiration is chiefly between results obtained with different amounts of acetate. Similar results in 
this respect were obtained regardless of the past history of the cells or the pH of incubation. Such variations are irrelevant to the conclusion that neither growth medium nor $\mathrm{pH}$ alters the efficiency of acetate metabolism by Euglena.

Euglena incubated on acetate consumed $\mathbf{0 . 8 4} \mu$ mole of $\mathrm{O}_{2}$ for each $\mu$ mole of acetate utilized, equivalent to a $42 \%$ oxidation of this substrate, independent of the experimental conditions. Similar values have been reported for other organisms. Barker (1936) observed at $50 \%$ oxidation of acetate with Prototheca zopfi, a colourless alga. Using a differential calorimetric technique Blum, Podolsky \& Hutchens (1951) found that Chilomonas paramecium oxidized $40 \%$ of the available acetate. Cirillo's data (1956) indicate that Polytoma uvella, a phytoflagellate, oxidized $46 \%$ of the available acetate.

Assuming that all the acetate not oxidized was assimilated by the cells, the oxidation: assimilation ratio of acetate was $\mathbf{0 . 7 2}$ for Euglena. The respiratory quotient of acetate was $1 \cdot 0$, independent of the experimental conditions; $0.84 \mu$ mole of $\mathrm{CO}_{2}$ was produced for each $\mu$ mole of acetate utilized. If all the acetate not oxidized were converted into a carbohydrate-like material, the empirical equation for the process would then be:

$$
\mathrm{CH}_{3} \mathrm{COOH}+0 \cdot 84 \mathrm{O}_{2} \rightarrow 0 \cdot 84 \mathrm{CO}_{2}+0 \cdot 84 \mathrm{H}_{2} \mathrm{O}+1 \cdot 16 \mathrm{CH}_{2} \mathrm{O} \text {. }
$$

This equation satisfies the theoretical conditions for the simultaneous oxidation of acetate and its conversion to carbohydrate, and the respiratory quotient and percentage oxidation experimentally observed. The results are thus consistent with the simultaneous oxidation and conversion to carbohydrate of acetate, but cannot be considered proof that such is the case.

Addition of ethanol to Euglena resulted in the consumption of 1.17 $\mu$ mole of $\mathrm{O}_{2}$ for each $\mu$ mole of ethanol utilized, equivalent to the complete oxidation of $39 \%$ of this substrate, independent of the experimental conditions. Again assuming that all the substrate not oxidized was assimilated by the cells, the oxidation: assimilation ratio of ethanol was $\mathbf{0 \cdot 6 4}$. If all the ethanol not oxidized were converted into a carbohydrate-like material, the theoretical equation for this simultaneous oxidation and synthesis may be represented as (based on the $\mathrm{O}_{2}$ : ethanol ratios)

$$
\mathrm{C}_{2} \mathrm{H}_{5} \mathrm{OH}+1 \cdot 17 \mathrm{O}_{2} \rightarrow 0 \cdot 17 \mathrm{CO}_{2}+1 \cdot 17 \mathrm{H}_{2} \mathrm{O}+1 \cdot 83 \mathrm{CH}_{2} \mathrm{O} \text {. }
$$

The respiratory quotient predicted by this equation is $\mathbf{0 \cdot 1 5}$, while the experimentally determined respiratory quotient for ethanol oxidation was $\mathbf{0 \cdot 3 3}$. Instead of $0 \cdot 17 \mu$ mole of $\mathrm{CO}_{2}$ being produced for each $\mu$ mole of ethanol utilized, it was found that $0.39 \mu$ mole of $\mathrm{CO}_{2}$ was produced. The results do not agree with the assumption that carbohydrate is the sole synthetic product of ethanol metabolism.

Lewin (1954) reported an adaptation of Chlamydomonas dysosmos apparently involving their ability to assimilate acetate. The cells oxidized acetate at once, but a $60 \mathrm{~min}$. exposure period was necessary before assimilation began.

Although it is not pointed out in the text, the data of Tanenbaum (1956, figs. 1, 2) indicate that ethanol-grown Acetobacter also adapt to acetate. $\mathbf{O}_{2}$ consumption and $\mathrm{CO}_{2}$ production due to acetate reached maximum rates only 
after a lag of about $10 \mathrm{~min}$. On ethanol, $\mathrm{CO}_{2}$ production was similarly delayed, but $\mathrm{O}_{2}$ consumption began immediately at its maximum rate. This suggests that, in this case, ethanol is promptly oxidized to the level of acetate, but acetate cannot be oxidized without a brief adaptation period. In Euglena, the extent of oxidation of both ethanol and acetate was constant under all experimental conditions. There is evidence (Danforth \& Wilson, 1957) that the adaptive change in the rate of acetate metabolism of Euglena involves an increased permeability to acetate ions. Thus, it would appear that, in three different micro-organisms which show adaptive changes in acetate metabolism, three distinct adaptive mechanisms are involved.

Conditions markedly affecting the rate of substrate oxidation in Euglena, such as adaptation to acetate, altered $\mathrm{pH}$ and lowered substrate concentration, had no effect upon the extent of oxidation. The oxidation: assimilation ratios of these substrates did not vary in response to environmental changes. It is reasonable to conclude that under these experimental conditions, the oxidative metabolism of Euglena is not regulated by changes in the extent to which a substrate is oxidized or incorporated. It is possible that other conditions might alter these oxidation-assimilation ratios. Cirillo (1956) reported a $15 \%$ increase in the rate of acetate respiration and the extent of total oxidation in the presence of $\mathrm{NH}_{4} \mathrm{Cl}$ by Polytoma. The effect of an exogenous nitrogen source on the extent of acetate and ethanol oxidation has not been studied in Euglena.

This study was aided by a grant from the American Cancer Society. This report is adapted from a thesis presented by one of the authors (B.W.W.) in partial fulfilment of the requirements for the degree of Master of Science at the Illinois Institute of Technology.

\section{REFERENCES}

Barker, H. A. (1936). The oxidative metabolism of the colorless alga, Prototheca zopfii. J. cell. comp. Physiol. 8, 231.

Blum, J. J., Podolsky, B. \& Hutchens, J. O. (1951). Heat production in Chilomonas. J. cell. comp. Physiol. 37, 403.

Cirillo, V. P. (1956). Induced enzyme synthesis in the phytoflagellate, Polytoma. J. Protozool. 3, 69.

Danforth, W. F. \& Wilson, B. W. (1957). Adaptive changes in the acetate metabolism of Euglena. J. Protozool. 4, 52.

Hutner, S. H. \& Provasoli, L. (1951). In Biochemistry and Physiology of Protozoa, Vol. 1, p. 27, ed. by Hutner, S. H. and Lwoff, A. New York: Academic Press Inc.

LEwin, R. A. (1954). The utilization of acetate by wild-type and mutant Chlamydomonas dysosmos. J. gen. Microbiol. 11, 459.

SyrETT, P. J. (1951). The effect of cyanide on the respiration and the oxidative assimilation of glucose by Chlorella vulgaris. Ann. Bot., Lond. 15, 473.

Tanenbaum, S. W. (1956). The metabolism of Acetobacter peroxidans, I. Oxidative enzymes. Biochim. biophys. Acta, 21, 335.

UMbreIt, W. W., BurRis, R. H. \& Stauffer, J. F. (1949). Manometric Techniques and Tissue Metabolism. Minneapolis: Burgess Publishing Co. 